\title{
Bacampicillin to treat non-gonococcal urethritis in men: pilot study
}

\author{
C T LEE, * K B LIM, * T THIRUMOORTHY, * M NADARAJAH $\dagger$ \\ From the *Middle Road Hospital, and the †Department of Pathology, Singapore General Hospital, Singapore
}

SUMMARY Of 84 men with non-gonococcal urethritis (NGU), 24 yielded Chlamydia trachomatis by either cell culture or MicroTrak immunofluorescence test. All 84 were treated with bacampicillin 800 $\mathrm{mg}$ twice a day for seven days. Five (one chlamydia positive) defaulted from follow up 10 to 14 days after the start of treatment. Of the 23 chlamydia positive patients who attended follow up, 22 became chlamydia negative; 14 of the 23 patients also became asymptomatic and had normal urethral smears. Of the 56 chlamydia negative patients who attended follow up, 21 were cleared of their urethritis.

Two patients reported side effects; one drowsiness and one mild diffuse alopecia. Bacampicillin may therefore be a safe and effective alternative to tetracycline or erythromycin in treating chlamydial urethritis in men.

Chlamydial infections are becoming increasingly common in many parts of the world. In fact, they are the most rapidly increasing sexually transmitted disease (STD) apart from the acquired immune deficiency syndrome (AIDS). ${ }^{\prime}$ Chlamydiae are not only a major cause of genital infections in both men and women, but also cause serious complications, especially in women, which often lead to infertility. In men, Chlamydia trachomatis is the organism most often isolated from patients with non-gonococcal urethritis (NGU). ${ }^{2}$ Tetracyclines are generally used as the first line antimicrobial agents to treat chlamydial infections, and erythromycin base or stearate are alternatives for patients in whom tetracyclines are contraindicated or not tolerated. Ampicillins have moderate activity against $C$ trachomatis; the minimum inhibitory concentrations of ampicillin, pivampicillin, and amoxycillin being $0 \cdot 25,0 \cdot 25$, and $2 \mathrm{mg} / \mathrm{l}$ respectively. ${ }^{34}$ Amoxycillin $750 \mathrm{mg}$ given orally three times a day for 10 days has apparently eliminated chlamydiae from six men with NGU followed up for 24 to 48 days. ${ }^{5}$ Pivampicillin 1.5 to $3 \mathrm{~g}$ a day orally for 10 days has been found to be highly effective in eradicating $C$ trachomatis from the lower genital tracts of men and women. ${ }^{3}$

Bacampicillin hydrochloride is an ester prodrug of ampicillin. It is almost completely (98\%) absorbed after being taken by mouth and is rapidly hydrolysed in the blood to its active metabolite, ampicillin. ${ }^{67}$

\footnotetext{
Address for reprints: Dr C T Lee, Middle Road Hospital, 250 Middle Road, Singapore 0718
}

Accepted for publication 30 May 1988
Bacampicillin is absorbed better and faster than ampicillin; a single oral $500 \mathrm{mg}$ dose gives rise to higher peak serum concentrations than a single intramuscular $500 \mathrm{mg}$ dose of ampicillin. ${ }^{8}$ Bacampicillin therefore has better pharmacokinetic properties than ampicillin and shows potential as an effective agent against $C$ trachomatis.

This study was designed to evaluate the efficacy and safety of bacampicillin in treating men with either chlamydia positive or chlamydia negative NGU.

\section{Patients, materials, and methods}

In March to October 1986 we enrolled into the study 84 men aged 18 or more with symptoms or signs, or both, of urethritis, whose diagnosis was confirmed by urethral smears containing more than four pus cells per high power $(x 1000)$ but no intracellular Gram negative diplococci. Patients with histories of allergy to penicillin or who had received antimicrobial agents in the preceeding two weeks were excluded from the study.

At the first visit patients were examined with particular attention to the presence of urethral discharge and meatitis. Urethral material for staining was collected with sterile platinum loops and was inoculated direct on to modified Thayer-Martin medium for culturing for Neisseria gonorrhoeae. Urethral smears were also taken to identify $C$ trachomatis. Patients were then given bacampicillin hydrochloride $800 \mathrm{mg}$ twice a day for seven days. They were advised to abstain from sexual intercourse and to avoid taking any other antibiotics during the study 
period, and were requested to return with a full bladder (having held urine for at least four hours) 10 to 14 days after the start of treatment.

At each follow up visit patients were interviewed regarding further sexual exposure, interim medication, and symptoms. Side effects caused by the medication that were spontaneously reported by patients, observed by the investigator, or reported by the patients after non-leading questions were recorded as being mild, moderate, or severe. Patients were then examined, and urethral smears were taken for Gram staining and identification of $C$ trachomatis.

At the first and follow up visits, we initially performed only cell cultures for $C$ trachomatis. We also performed the MicroTrak (Syva, Maidenhead, England) direct immunofluorescence test when it became available. Later most of the urethral specimens were examined by MicroTrak, as a local study had found that MicroTrak had a sensitivity of $80 \%$ and a specificity of $91 \%$ compared with cell culture (Kamarudin A, et al, unpublished observation).

\section{LABORATORY METHODS TO IDENTIFY \\ C TRACHOMATIS}

Specimens were obtained with sterile Dacron swabs on a thin metal wire (Imagen chlamydia specimen collection swabs; Boots-Celltech Diagnostics, USA) inserted 3 to $5 \mathrm{~cm}$ into the urethra and rotated several times. Specimens in sucrose phosphate (2 SP) medium containing antibiotic were transported to the laboratory for inoculation into cycloheximide treated McCoy cells by centrifugation and for chlamydial culture. After being incubated for two to three days, the monolayers were fixed in methanol, stained with Giemsa's stain, and then examined by dark ground microscopy. $C$ trachomatis was considered to be present if characteristic intracytoplasmic inclusion bodies were detected.

Specimens for MicroTrak direct immunofluorescence studies were rolled in a $6 \mathrm{~mm}$ well Teflon coated glass microscope slide, fixed with acetone, and air dried. The fixed slide was subsequently stained with monoclonal antibody specific to chlamydiae, which was conjugated with fluorescein isothiocyanate (FITC). The stained smear was examined using an Olympus Venox fluorescence microscope with excitation filter BG-12 and a $\times \mathbf{4 0}$ objective. The smear was considered to be positive when 10 or more elementary bodies staining bright apple green were observed against a background of cellular materials.

The patients were chlamydia positive or chlamydia negative according to the results of the chlamydial tests before treatment. In the chlamydia positive patients, clinical cure was defined by the absence of symptoms and signs and by normal urethral smears,
Table 1 Results of cell culture and MicroTrak immunofluorescence tests at first visits of 84 patients

$\left.\begin{array}{lrr}\hline \text { Results of tests } & \multicolumn{2}{c}{\text { No }} \\ \hline \text { Cell culture positive, MicroTrak negative } & 9 \\ \text { Cell culture positive } & 7 & \\ \text { MicroTrak negative } & 6 & 24 \\ \text { Cell culture positive, MicroTrak negative } & 2 & \\ \text { Cell culture negative, MicroT Trak negative } & 25 & \\ \text { Cell culture negative } & 13 & \\ \text { MicroTrak negative } & 22 & 60 \\ \text { Cell culture negative, MicroTrak positive } & 0 & \end{array}\right\}$

and microbiological cure was defined by negative results to chlamydial tests 10 to 14 days from the start of treatment. In the chlamydia negative patients, cure was defined clinically, based on the absence of symptoms and normal urethral smears.

\section{Results}

Of 84 patients (mean age 28 (range 18-45)) who participated in the study, five (one chlamydia positive) defaulted from follow up, leaving 79 patients for the evaluation of response. At the first visit; cultures for $N$ gonorrhoeae were all negative in the 84 patients included in the study.

Table 1 shows the results of the chlamydial tests before treatment, chlamydiae being identified in 24 of the 84 patients by cell culture or MicroTrak, or both.

Table 2 shows the results of treatment. Nine of the 23 chlamydia positive patients who attended follow up still had symptoms or signs, or both, of urethritis, although their chlamydial test results were negative after treatment.

Two patients reported side effects after non-leading questions; one was drowsiness and one was mild diffuse alopecia. These two side effects were considered unlikely to be related to the treatment.

\section{Discussion}

The results of the study reported here showed that bacampicillin hydrochloride $800 \mathrm{mg}$ twice a day for seven days was effective against chlamydial urethritis in men. The high cure rate of $96 \%(22 / 23)$ in the

Table 2 Results of treating 79 men with non-gonococcal urethritis with bacampicillin hydrochloride

\begin{tabular}{llll}
\hline & No & $\begin{array}{l}\text { No cured } \\
\text { microbiologically }\end{array}$ & $\begin{array}{l}\text { No cured } \\
\text { clinically }\end{array}$ \\
\hline Chlamydia positive & 23 & 22 & 14 \\
Chlamydia negative & 56 & Not applicable & 21 \\
\hline
\end{tabular}


chlamydia positive patients compared favourably with $85-95 \%$ cure rates obtained by Washington using tetracyclines and erythromycin. ${ }^{9}$ In our patients with chlamydia negative NGU, however, bacampicillin had a lower cure rate $(38 \%, 21 / 56)$ than tetracycline, which William et al found cured $56 \%$ of 84 chlamydia negative men. ${ }^{10}$

Tetracyclines are absorbed somewhat irregularly from the gastrointestinal tract, and the absorption of tetracyclines and erythromycins are affected by food. ${ }^{11}{ }^{12}$ The absorption of bacampicillin, on the other hand, is not affected by the intake of food.

The pattern of adverse drug reactions to bacampicillin follows that of other aminopenicillins, with a predominance of dermatological reactions and gastrointestinal symptoms. The incidence of reports of side effects, however, was at least half that for oral ampicillin. The side effects to bacampicillin given in dosages varying from $400 \mathrm{mg}$ twice a day to $800 \mathrm{mg}$ three times a day for 10 days to 5316 patients included skin manifestations (2\%), upper gastrointestinal symptoms (3\%), and lower gastrointestinal symptoms (2\%) (Pichler $\mathrm{H}$, unpublished observation). The two side effects (drowsiness and diffuse loss of hair) noted in our study were probably not related to the intake of bacampicillin.

Concomitant gonococcal and chlamydial infections are common in many parts of the world. C trachomatis has been recovered from $27-63 \%$ of women with endocervical gonorrhoea and from $4-33 \%$ of men with urethral gonorrhoea.9 In Singapore, $C$ trachomatis has been isolated from $26 \%(35 / 136)$ of men with gonococcal urethritis. ${ }^{13}$ Bacampicillin $1600 \mathrm{mg}$ given with probenecid $1 \mathrm{~g}$ has been found to be highly effective (more than $95 \%$ ) against infections with non$\beta$-lactamase producing gonococci. ${ }^{14}$ In geographical areas with a low prevalence of infection with $\beta$ lactamase producing gonococci, therefore, concomitant gonococcal and chlamydial infection may be treated with bacampicillin hydrochloride $1.6 \mathrm{~g}$ and probenecid $1 \mathrm{~g}$ followed by bacampicillin $800 \mathrm{mg}$ twice daily for seven days. In areas with a high prevalence of infection with $\beta$ lactamase producing gonococci, however, the use of bacampicillin is not advisable, as it is not effective against $\beta$ lactamase producing gonococci.

In conclusion, $29 \%(24 / 84)$ of the men with NGU who we studied in Singapore were infected with $C$ trachomatis. Bacampicillin $800 \mathrm{mg}$ twice a day for seven days seems to be efficacious against chlamydial urethritis in men. It may be particularly useful in patients who are allergic to or intolerant of both tetracycline and erythromycin. It may also be a useful alternative to erythromycin in treating chlamydial infections during pregnancy. The few and mild adverse effects found by us confirm previous experience with bacampicillin. Further studies of the effect of bacampicillin against chlamydial infections should be conducted with a longer follow up period in a larger group of patients, including women.

We thank Astra Alab AB, Sodertalje, Sweden, for supplying the drug for the study; and the staff of the Middle Road Hospital for their co-operation in this study, particularly Miss Boey of the Laboratory in Middle Road Hospital for processing and reading the MicroTrak immunofluorescence test slides.

\section{References}

1 Walter ES, King KH. Chlamydia trachomatis infections of the adult. In: Holmes KK, Mårdh P-A, Sparling PF, Wiesner PJ, eds. Sexually transmitted diseases. New York: McGraw-Hill, 1984:258-70.

2 Lim KB, Thirumoorthy T, Lee CT, Sng EH, Tan T. The microbiology of non-gonococcal urethritis in Singapore. Annals of the Academy of Medicine, Singapore 1985;14:686-8.

3 Birger R, Marie C, Ellis F. Pivampicillin in treating genital infection with Chlamydia trachomatis. Genitourin Med 1985; 61:264-5.

4 Ridgway GL, Owen JM, Oriel JD. The antimicrobial susceptibility of Chlamydia trachomatis in cell culture. British Journal of Venereal Diseases 1978;54:103-6.

5 Bowie WR, Russell AE, Holmes KK. Eradication of Chlamydia trachomatis from the urethra of men with non-gonococcal urethritis by treatment with amoxycillin. Sex Transm Dis 1981;8:79-81.

6 Bodin NO, Ekstrom B, Forsgren U, et al. Bacampicillin, a new orally well-absorbed derivative of ampicillin. Antimicrob Agents Chemother 1985;8:518-25.

7 Sjovall J, Magni L, Bergan T. Pharmacokinetics of bacampicillin compared with those of ampicillin, pivampicillin and amoxycillin. Antimicrob Agents Chemother 1978;13:90-6.

8 Bergan T. Pharmacokinetics: comparison of bacampicillin and parenteral ampicillins. Antimicrob Agents Chemother 1987; 13:971-4.

9 Washington AE. Update on treatment recommendations for gonococcal infections. Rev Infect Dis 1982;4suppl:758-71.

10 William RB, John SY, Archana F, Hugh DJ. Tetracycline in nongonococcal urethritis. British Journal of Venereal Diseases 1980;56:332-6.

11 Ernest J. Chloramphenicol and tetracyclines. In: Katszung BG, ed. Basic and clinical pharmacology. Los Altos, California, USA: Lange Medical, 1984:532-7.

12 Welling PG. Influence of food and diet on gastrointestinal drug absorption: a review. J Pharmacokinet Biopharm 1977;5:321-5.

13 Lee CT, Thirumoorthy T, Lim KB, Sng EH, Tan T. Norfloxacin in the treatment of uncomplicated gonorrhoea in Singapore. JAMA 1986;special supplement:42-4. (ASEAN symposium on quinolones in the treatment of gonorrhoea. Science Press Congress Archives 86001.)

14 Romanowski B. Clinical evaluation of oral bacampicillin in the therapy of uncomplicated gonorrhoea. Can J Public Health 1985;76:98-100. 